\title{
REPRODUÇÃO ASSISTIDA: ASPECTOS ÉTICOS E LEGAIS. PRODUÇÃO CIENTÍFICA EM PERIÓDICOS ONLINE
}

\author{
Sarah Lins dos Santos ${ }^{1}$, Sérgio Ribeiro Santos ${ }^{2}$
}

Resumo: Objetivos: verificar as modalidades da produção científica acerca dos aspectos éticos e legais da prática da reprodução assistida durante o período de 2006 a 2011; identificar as áreas do conhecimento e a formação dos autores incluídos na pesquisa; investigar os enfoques nas publicaçóes inclusas no estudo. Trata-se de pesquisa documental, que teve como fonte de dados artigos nacionais e internacionais publicados sobre a temática disponível na Biblioteca Virtual em Saúde. O universo do estudo foi constituído por 884 publicaçóes, das quais 8 fizeram parte da amostra. A partir da análise do material empírico, constatou-se que a maior parte das publicaçóes é composta por artigos originais. Quanto à área do conhecimento das publicaçóes, destacam-se Medicina (12,8\%) e Direito (2,2\%). Foram identificadas duas categorias: compreensão jurídica e médica sobre a reproduçáo assistida e os aspectos bioéticos. O estudo constatou uma quantidade pouca expressiva de produção científica acerca dessa temática. Contudo, os resultados permitiram a visualização de pesquisas que apresentaram propostas inovadoras sobre a valorização do direito à vida e da garantia dos direitos humanos fundamentais.

Palavras-chave: técnicas reprodutivas, bioética, ética médica

\section{Reproducción asistida: aspectos éticos y legales. Producción científica en periódicos online}

Resumen: Objetivos: verificar las modalidades de producción científica sobre aspectos éticos y legales de la práctica de la reproducción asistida, durante el periodo 2006-2011; identificar las áreas de conocimiento y la formación de los autores incluidos en la investigación; investigar los enfoques de las publicaciones incluidas en el estudio. Se trata de una investigación documental, que tuvo como fuente de datos artículos nacionales e internacionales publicados sobre la temática en la Biblioteca Virtual de Salud. El universo del estudio fue constituido por 884 publicaciones, de las cuales solo 8 fueron parte de la muestra. A partir del análisis del material empírico, se constató que la mayor parte de las publicaciones se compone de artículos originales. En cuanto al área del conocimiento de las publicaciones, se destacan Medicina (12,80\%) y Derecho $(2,25 \%)$. Fueron identificadas dos categorías sobre reproducción asistida: comprensión jurídica y médica y aspectos bioéticos. El estudio constató una cantidad no expresiva de producción científica acerca de los aspectos bioéticos de la reproducción asistida. Con todo, los resultados permitieron visualizar estudios que presentan propuestas innovadoras sobre la valorización del derecho a la vida y la garantía de los derechos humanos fundamentales.

Palabras clave: técnicas reproductivas, bioética, ética médica

\section{Assisted reproduction: legal and ethical aspects. Scientific production in on-line journals}

\begin{abstract}
Objectives: to examine the modalities of scientific production on legal and ethical aspects of assisted reproduction between 2006-2011; to identify the areas and training of researchers involved; to investigate the points of view included in the studies. The source were articles included in the Virtual Health Library. The universe was 884 publications, 8 of which were part of the sample. The empirical analysis demonstrated that the majority were original publications. Regarding knowledge area, 12,80\% belonged to medicine and 2,25 \% to Law. Two categories were identified: medical and juridical understanding and bioethics. The study revealed an amount of non scientific literature on bioethical aspects of assisted reproduction. Some studies were identified presenting innovative proposals on valorization of the right to life y the safeguard of fundamental human rights.
\end{abstract}

Key words: reproductive techniques, bioethics, medical ethics

\footnotetext{
${ }^{1}$ Fisioterapeuta do Serviço de Fisioterapia Infantil do Hospital Universitário Lauro Wanderley. Mestranda em Enfermagem pela Universidade Federal da Paraíba, Brasil

Correspondência: sarahlins44@gmail.com

${ }^{2}$ Enfermeiro. Doutor em Sociologia. Professor Associado do Departamento de Enfermagem Clínica e do Programa de Pós-Graduação em Enfermagem da UFPB, Brasil
} 


\section{Introdução}

O surgimento progressivo da medicina do século XIX não pode ser dissociado das políticas de saúde e da consideraçáo das doenças como problema político e econômico. Tampouco, ele não pode ser dissociado da compreensão da família, não só como um sistema de parentesco e de transmissão de bens, mas também como local de "fabricação", nas melhores condiçôes possíveis, de um ser humano. A reprodução assistida interfere nos desejos individuais e normas no campo da reprodução do casamento e da família. A medicina, depois das análises realizadas por Michel Foucault, tem sido indicada como uma das instituiçóes a partir da qual os sujeitos e suas práticas são normatizadas(1).

Procriar e constituir família são aspectos altamente valorizados nas sociedades e a infertilidade é repudiada como um infortúnio. Em nossos dias, a procriação se liga não apenas à idéia de felicidade, mas também a de êxito pessoal. Nesse sentido, na maternidade e na paternidade são mobilizados traços arraigados das identidades individuais e sociais dos sujeitos humanos. Por tudo isso, é possível afirmar que a impossibilidade de reprodução biológica fragiliza, de forma importante, homens e mulheres que se encontram em união(2).

As práticas de reprodução assistida correspondem a um Modus Operandi tradicional acrescido de um procedimento que introduz a prática de reprodução sem relaçóes sexuais, restrita a uma parcela da população, e com diferenças no seu uso em termos populacionais e grupos sociais. Elas têm sua importância simbólica na evolução contemporânea da reprodução, por afastar a procriação da "natureza" e do "desejo sexual". Na reprodução assistida, a fragmentação do processo reprodutivo abre espaço para o surgimento de doaçóes de gametas que, de alguma forma, partilham questôes relacionadas à doação de órgãos(3).

A abordagem médica deste problema —a ausência não desejada de filhos- é, entretanto, atraves- sada por contradiçóes. Primeiramente, a ausência de filhos não pode ser caracterizada como sendo propriamente uma doença, que causa danos físicos ou riscos à saúde e à vida, embora muito sofrimento possa ser implicado neste problema. Além disso, a reprodução assistida interfere com desejos individuais e normas sociais no campo da reprodução, do casamento e da família. Finalmente, a sua aplicação tem desdobramentos que ultrapassam em muito uma terapêutica individual ao atingir geraçôes futuras e envolver questóes relacionadas ao início da vida e ao próprio valor da vida humana(4).

Em função destes aspectos éticos, apresentam-se graves dilemas éticos e bioéticos para os médicos e a Medicina, mesmo quando as intervençóes propostas são consentidas, do ponto de vista formal, e realizadas em nome da autonomia individual. A vulnerabilidade dos sujeitos em face da biotecnologia reprodutiva comporta também um elemento complicador, que é o diferencial de gênero. Sendo uma tecnologia voltada na maior parte das vezes para o casal, cabe pensar que na tomada de decisão e no consentimento estão implicados sujeitos de sexos diferentes.

A capacidade de manipulação da vida ocorre no momento em que essas tecnologias introduziram uma ruptura na continuidade do processo feminino de procriação, ao possibilitar a ocorrência da gravidez sem sexo e a fecundação fora do corpo, substituindo a função corporal. Esse desenvolvimento torna-se possível no modo de compreensão da reprodução como um processo de causalidade de eventos e mecanismos que podem ser fragmentados e influenciados independentemente. Tal forma de conceitualizar a reprodução permite dissecar todo o processo em sequências de estágios autocontidos, isolados e manipuláveis.

A manipulação das tecnologias assistidas legitima a finalidade que se pretende alcançar. Entretanto, existem polêmicas no tocante ao aspecto moral desse ato. Para muitos, constitui-se em prática imoral, visto que interrompe o âmbito íntimo 
da vida sexual do casal e coisifica a vida humana embrionária, destruindo outros casos de embrióes sobrantes. Há um forte embate sobre a finalidade terapêutica destas técnicas e a possibilidade de tornar realidade alguns casos. Com a demanda social e as leis do mercado, este fato é impulsionado a atingir expectativas desmedidas podendo levar a ciência médica a extremos inesperados, permitindo a abertura de interrogantes éticos sobre a finalidade da medicina como ciência.

Diante dessas consideraçóes, é sobremaneira importante a produçấo de novos conhecimentos acerca dos aspectos éticos e legais da utilização da reprodução assistida. Daí o nosso interesse, como profissionais de saúde, em realizar um estudo, cujo foco norteador parta dos seguintes questionamentos: quais as modalidades da produção científica acerca dos aspectos éticos e legais da reprodução assistida disseminada em periódicos online no período de 2006 a 2011? Quais as áreas do conhecimento e a formação dos autores dos artigos inseridos na pesquisa? Quais os enfoques abordados nas publicaçôes inclusas no estudo?

$\mathrm{Na}$ busca de responder aos questionamentos propostos, o presente estudo tem por objetivos: analisar as modalidades da produção científica dos aspectos éticos e legais da reproduçáo assistida, disseminada em periódicos online, no período de 2006 a 2011; identificar as áreas do conhecimento e a formação dos autores incluídos na pesquisa; $\mathrm{e}$, investigar os enfoques nas publicaçóes inclusas no estudo.

\section{Metodologia}

Trata-se de uma pesquisa documental, com abordagem quantitativa, cujas fontes de dados são artigos nacionais e internacionais em periódicos online a respeito da visão da bioética na reprodução assistida durante o período de 2006 a 2011. Para viabilizar a coleta do material empírico, utilizou-se a Biblioteca Virtual em Saúde (BIREME) nas seguintes bases de dados: Scientific Eletronic Library Online (SciELO); Literatura Latino-
-Americana e do Caribe em Ciências da Saúde (LILACS); Sistema de Informação da Biblioteca da Organização Mundial da Saúde (WHOLIS); Literatura Internacional em Ciências da Saúde (Medline e PubMed), e acervo da Biblioteca da Organização Pan-americana da Saúde (PAHO). A busca bibliográfica foi realizada a partir das seguintes palavras-chave: reprodução assistida, direitos, medicina.

O período da coleta de dados ocorreu durante o mês de julho de 2011. O universo do estudo foi constituído por 884 publicações, sendo 874 artigos e 10 teses. Desse total, oito publicaçóes fizeram parte da amostra, sendo sete artigos e uma tese. Os critérios de inclusão da amostra foram: o estudo deveria abordar no título a temática investigada; apresentar o texto na íntegra e nos idiomas português, inglês ou espanhol.

As etapas operacionais do estudo foram: seleção das bases de dados e portais; elaboração de critérios de inclusão e exclusão; seleção dos artigos que abordavam a temática; extração dos dados das publicaçóes investigadas, a partir dos objetivos propostos; agrupamento dos itens selecionados por categorias; apresentaçáo dos dados obtidos por meio de representação gráfica e análise dos dados.

Para organização das informaçóes contidas nas publicações científicas encontradas foi utilizado um instrumento para a coleta de dados, contendo título, ano e natureza da publicação; área de formaçãoo e titulação dos pesquisadores; objetivos, metodologia e as consideraçôes finais dos trabalhos.

A análise de conteúdo foi realizada em três etapas: 1) a pré-análise; 2) a exploração do material; 3) o tratamento dos resultados e interpretação. A primeira etapa foi a fase de organizaçáo: leitura flutuante, hipóteses, objetivos e elaboração de indicadores que fundamentem a interpretação. $\mathrm{Na}$ segunda etapa, os dados foram codificados a partir das unidades de registro. Na última etapa foi realizada a categorização, que consiste na classifi- 
cação dos elementos, segundo suas semelhanças e por diferenciação, com posterior reagrupamento, em função de características comuns.

\section{Resultados}

O material empírico do estudo foi constituído por oito publicaçôes. No que concerne a modalidade dos artigos, os resultados revelaram que todos eram originais. No tocante a origem deles, seis eram nacionais e dois internacionais. Quanto aos anos de publicação, em 2010 se observou a maior concentração de publicaçóes, com quatro artigos, enquanto o período de 2006 a 2009 contou com as seis restantes.

A produção de artigos originais que abordam a temática da reprodução assistida na visão da bioética vem aumentando mais em nível nacional, sendo marcada a produçáo expressiva no ano de 2010. Isso nos mostra a preocupação dos pesquisadores em evidenciar a prática da reprodução assistida sob o ponto de vista da bioética.

Quanto ao cenário nacional, percebeu-se um avanço nas pesquisas sobre reprodução assistida em nível de pós-graduação. Em relação à área de conhecimento das publicaçóes e da formação dos autores, a figura 1 revela que a maioria é do campo da Medicina, destacando-se ainda o Direito, seguido pela Antropologia e pela Psiquiatria.

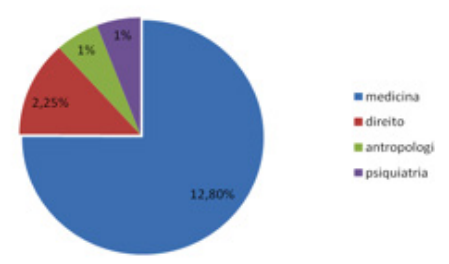

Figura 1- Distribuição das áreas de concentração dos artigos inclusos no estudo, 2011.

Diante do exposto, percebe-se grande interesse no campo da medicina referente à visão da bioética sobre a prática da reprodução assistida. $\mathrm{Na}$ busca pelo saber médico foi observado que a bioética proporciona reflexôes explícitas, uma vez que leva em consideração a dignidade humana e os direitos dos cidadãos enquanto usuários de serviços de saúde. Além disso, o olhar bioético contribui para a ampliação das reflexôes acerca do alcance e da garantia dos direitos fundamentais dos indivíduos, parte vital da composição do direito à cidadania, podendo ser entendido como a própria dimensão ética das políticas públicas(3).

Quanto aos enfoques das publicações inseridas no estudo foi possível extrair duas categorias a partir dos títulos dos artigos investigados, conforme expresso nos quadros 1 e 2 :

\begin{tabular}{|l|}
\hline $\begin{array}{l}\text { CATEGORIA I } \\
\text { Compreensão jurídica e médica sobre a reprodução } \\
\text { assistida }\end{array}$ \\
\hline $\begin{array}{l}\text { A compreensão jurídica, médica e leiga do embrião em } \\
\text { Portugal: um alinhamento com a biologia. }\end{array}$ \\
\hline $\begin{array}{l}\text { Cessão temporária de útero: aspectos éticos e ordenamento } \\
\text { jurídico vigente }\end{array}$ \\
\hline $\begin{array}{l}\text { Filiação e tecnologias de reprodução assistida: entre a } \\
\text { Medicina e Direito }\end{array}$ \\
\hline $\begin{array}{l}\text { Injeção intracitoplasmática de espermatozóides: questóes } \\
\text { éticas e legais }\end{array}$ \\
\hline
\end{tabular}

Quadro 1: Título das publicaçôes inseridas na categoria 1compreensão jurídica e médica sobre a reprodução assistida.

De acordo com os títulos das publicaçóes apresentadas na categoria 1 , destacados no quadro 1 , constata-se o interesse dos pesquisadores em, por um lado, buscar estratégias para a formulação de leis que inviabilizem práticas como a doação de gametas e, por outro, legalizar a prática da reprodução assistida em casos de mulheres histerectomizadas, incapazes da maternidade por outra via. Enquanto nenhum projeto de lei no congresso for aprovado, seus limites sáo impostos por outros meios sociais que não o Direito, entre os quais se destacam os acordos entre os envolvidos e as normas éticas do Conselho Federal de Medicina(6).

A cessão temporária do útero não deve ter objetivo comercial ou lucrativo, sendo a gratuidade um 
dos limites impostos pelo ordenamento jurídico brasileiro, assim como pelas normas éticas que regem a reprodução assistida. $\mathrm{O}$ mesmo princípio rege a doação de gametas, uma vez que estabelece que o corpo humano e suas substâncias são objetos fora de comércio. A denominação "barriga de aluguel” é, portanto, considerada imprópria apesar de sua popularidade, já que não seria lícita a realização de um contrato oneroso(6).

O quadro 2 destaca os títulos das publicaçóes inseridas no estudo pertinentes à temática "Reprodução assistida: aspectos bioéticos", que problematiza a transformação da prática aqui discutida em comércio, além de avaliar os riscos aos quais a mulher estaria sujeita ao participar da reprodução assistida. Isso indica a importância da bioética na reprodução assistida para os pesquisadores.

\section{CATEGORIA II}

Reprodução assistida: aspectos bioéticos

El diálogo bioético en las técnicas de reproducción asistida.

Relación Mujer y Biotecnología: aproximación al impacto de la bioética.

Expectativa de mulheres à espera de reprodução assistida em hospital público do DF- estudo bioético.

Quadro 2: Títulos das publicaçôes inseridas no estudo relacionado a categoria II - reprodução assistida: aspectos bioéticos.

Os estudos direcionados à bioética, no contexto da utilização das técnicas de reprodução assistida em mulheres que desejam ter um filho são enfáticos, apesar de se apresentarem em pequeno número de publicaçóes. Isso mostra que os pesquisadores tentam, apesar da baixa demanda, produzir textos sobre a importância da preservação da vida, da dignidade humana e dos direitos dos cidadáos usuários dos serviços de saúde.

A fertilização in vitro, por exemplo, possibilita a fecundação em caso de problemas funcionais como a obstrução tubária. Outro exemplo se mostra na técnica de injeção intracitoplasmática de espermatozóide, uma forma de intervenção em nível celular, que torna viável a reprodução de homens sem espermatozóides. De fato, esta prática ainda está associada a alta taxa de fracassos, gestaçôes múltiplas, problemas de saúde como por exemplo: cistos ovarianos, ou mesmo na produção de embrióes excedentes, geradores de novas demandas altamente problemáticas, tornando -se prática controversa sob o ponto de vista da bioética(4).

A partir da análise qualitativa do material empírico do estudo, emergiram oito conclusóes sobre a reprodução assistida, segundo os aspectos éticos e legais mostrado no quadro 3:

Quanto à prática da reprodução assistida, faz-se necessário um olhar bioético para contribuir acerca dos direitos fundamentais do indivíduo.

Deve ser feita uma melhor reflexão desta prática, principalmente quanto aos riscos, limitaçóes e incertezas do tratamento, sob a ótica do biodireito.

Existe o perigo do cientificismo e da comercialização desta técnica. É necessário estabelecer condições para um diálogo médico-paciente, de forma a respeitar as normas éticas.

A bioética tem um papel muito importante em discernir como a sociedade incorpora mudanças tecnocientíficas, e como esta prática interfere na mulher como pessoa e interlocutor válido.

Os valores bioéticos são primordiais para a tutela dos valores humanos fundamentais; todavia, o desafio maior é estimular o desenvolvimento da ciência, sem deixar de considerar a necessidade do respeito à dignidade da pessoa humana.

Trata-se de uma questáo polêmica, na qual a população deve se posicionar eticamente, para a formulaçáo de leis que possam regulamentar certas práticas da reprodução assistida, para que as mulheres tenham acesso a este procedimento.

As autoridades devem se posicionar para defender os valores éticos de família naturalizada, valores capazes de inscrever o direito à filiação em moldes mais democráticos.

O Estado precisa rever os seus conceitos sobre a importância da bioética na defesa pela vida e, consequentemente, rever a prática da reprodução assistida, de maneira que o mesmo possa avaliar se esta prática satisfez a expectativa das mulheres ou não.

Quadro 3: Conclusôes dos pesquisadores a cerca dos aspectos éticos e legais da reprodução assistida. 


\section{Discussão}

Os estudos apresentados na categoria I, os autores afirmam que o Estado e a sociedade precisam rever os conceitos, objetivos, valores sociais, riscos e possíveis benefícios da prática da reprodução assistida. Foi observado que os autores questionam eticamente como esta prática está sendo utilizada sob o ponto de vista da bioética. Conhece-se pouco desta prática do ponto de vista sociológico, e o que a mesma representa para os próprios indivíduos 9.

Os autores8 ressaltam que, se por um lado a medicina proporciona este avanço, por outro, a falta de legislação específica causa risco aos médicos que as praticam nos pacientes e aos filhos gerados por meio delas, uma vez que na ausência norma jurídica, a tutela de direitos termina por ser prejudicada. Assim, verifica-se que apesar da reproduçâo assistida ser uma realidade social e científica, encontra-se ausente do mundo jurídico.

No que concerne a categoria II, a temática dos aspectos bioéticos que envolve a prática da reprodução assistida, apresentou um quantitativo de publicaçóes pouco expressivo, tendo em vista ser uma abordagem de grande relevância sob o ponto de vista, do direito á vida, estas publicações expõe de forma clara e concisa a mercantilizaçáo desta prática e as estratégias de manipulação do ser humano no momento da realização deste procedimento.

A bioética tem um papel importante em discernir como a sociedade incorpora os câmbios tecnocientíficos e, em consequência, como isto afeta a imagem da mulher como pessoa e como interlocutor válido. Assim, como examinar discussões dos alcances sociais que tenta incorporar as inovaçôes tecnológicas em torno dos neoconservadores responsáveis pelo mercado humano9.

É possível perceber a partir das conclusóes dos autores das referidas publicaçóes que o Estado preci- sa rever os seus conceitos sobre a importância da bioética na defesa pela vida e, consequentemente, rever a prática da reproduçáo assistida, de maneira que o mesmo possa avaliar se esta prática satisfez a expectativa das mulheres ou náo. Por outro lado, a prática da reprodução assistida veio para proporcionar uma nova expectativa de vida á mulheres histerectomizadas, oferecendo uma oportunidade de constituir uma família.

Percebe-se que as atuais políticas desenvolvidas no âmbito da reproduçáo medicamente assistida se consubstanciam num projeto técnico-genético e biopolítico que assenta, sobretudo, na socializaçấo da compreensão pública da ciência e da tecnologia a partir da biologização e genetização dos valores sociais. A emergência de novas formas de cidadania, paradoxalmente privatizadas e reconfiguradas como formas de cidadania íntimas e apolíticas, podem contribuir para a diluição e individualização das responsabilidades sociais no que concerne à gestáo dos riscos e das incertezas associados aos usos sociais dos embriōes humanos, o que pode restringir alguns dos direitos fundamentais dos cidadãos 3 .

A fusão entre os corpos embrionários, a tecnociência e a biomedicina afigura-se como um dos exemplos mais recentes que ilustra o esforço ontológico na insistência de um mundo natural ou biológico, ao qual o direito e a medicina parecem estar cada vez mais vinculados e subordinados. Este esforço ontológico reflete-se nas imagens sociais sobre o embrião humano, cujo estatuto médico e legal assenta, cada vez mais, na ideia de que há uma distinção entre a natureza e a pessoa humana, o que é sustentado pelas representaçóes sociais sobre o estatuto objetivo, racional e desinteressado da tecnociência e da biomedicina, o que pode contribuir para que os embrióes sejam cada vez mais submetidos a uma medicalização prematura associada à extensão espaço-temporal das fronteiras da vida 8 .

Desse modo, a bioética serve primordialmente como uma reflexão em torno de práticas sociais 
e, à medida que envolve os indivíduos, deve estimular que estes recuperem sua capacidade de indignação. A qualidade de vida é a própria vida e, se não houver um coletivo forte, a autonomia individual fica ameaçada: a justiça é o ordenamento social que permite a cada membro cobrir suas necessidades e manter suas opçóes de projeto de vida 7.

O biomercado tecnológico e a complexidade das escolhas morais surgidas do progresso científico devem nos levar a discutir e raciocinar sobre os casos especiais e a uma reflexão moralmente aceita, uma vez que a análise deve sempre partir da relação saúde e sociedade, para que assim possamos chegar às conclusóes bioéticas 10 .

\section{Conclusáo}

Tendo em vista os aspectos aqui abordados, constata-se que a discussão acerca dos aspectos éticos e legais da prática da reprodução assistida está em processo de desenvolvimento, como demonstram as publicaçóes investigadas. No entanto, a realidade das implementaçôes das leis sob a ótica da bioética referente à biotecnologia ainda é distante. A ausência de leis vigentes no país proporciona às mulheres maior liberdade de acesso a estas tecnologias, com o objetivo de alcançar uma tríade do seu projeto de felicidade: a realização da necessidade de ter um filho, o alcance de um filho perfeito e, como consequência, o seu projeto de felicidade, a constituição uma família.

Vale salientar que a quantidade de produçôes científicas em periódicos online no período investigado e que tratam dos aspectos bioéticos da reprodução assistida não é expressiva. Existe pouca publicação da temática referida, embora os estudos inseridos apresentem propostas inovadoras sobre a valorização do direito à vida e da garantia dos direitos humanos fundamentais.

É preciso questionar, de imediato, sobre os legitimados para fazer uso de tais métodos de reprodução assistida, uma vez que em nossa sociedade existem diferentes maneiras de se constituir um casal. Assim, a necessidade de se considerar juridicamente os valores bioéticos é primordial para a tutela dos direitos humanos fundamentais. Todavia, o desafio maior é estimular o desenvolvimento das ciências de maneira que a dignidade humana permaneça respeitada. 
Reprodução assistida: aspectos éticos e legais - Sarah Lins dos Santos, Sergio Ribeiro Santos

\section{Referências}

1. Foucault L. História da sexualidade I: Vontade de saber. Rio de Janeiro: Edições Graal; 1997.

2. Corrêa MV. A tecnologia a serviço de um sonho: um estudo sobre a reprodução assistida no Brasil. Tese. Rio de Janeiro: Universidade do Estado do Rio de Janeiro; 1997.

3. Borlot AMM, Trindade ZA. As tecnologias de reprodução assistida e as representaçôes sociais de filho biológico. Estudos de Psicologia 2004; 12(9):63-70.

4. Berlinguer G, Garrafa V. A mercadoria final: a comercialização de parte do corpo humano. Brasília: Editora Unb; 2001.

5. Corrêa MV. Novas tecnologias reprodutivas. Limites da biologia ou biologia sem limites? Rio de Janeiro: Editora UERJ; 2001.

6. Oliveira DCA, Borges JRE. Reprodução assistida: até onde podemos chegar? Compreendendo a ética e a lei. São Paulo: GAIA; 2000.

7. Leite EO. Procriaçôes artificiais e o Direito. São Paulo: Revista dos tribunais; 1995.

8. Clemente APP. Bioética início da vida: dilemas de forma interdisciplinar. Petrópolis: Vozes; 2006.

9. Lolas F. Valdebenito C. Relación mujer y biotecnología: aproximación al impacto de la bioética. Acta Bioethica 2006; 12(2).

10. Ventura M. Direitos reprodutivos no Brasil. São Paulo: Mventura; 2002.

Recebido: janeiro 11, 2012

Aceito: 15 março de 2012 